\title{
PENDAMPINGAN PROGRAM MENGAJI MENGGUNAKAN METODE IQRO' (TINGKAT DASAR) PADA ANAK-ANAK MELALUI PEMBERDAYAAN IPNU DAN IPPNU DI DESA KENONGO
}

\author{
Fathul Ulum ${ }^{1}$, Fitrotul Jannah², Deny Setiawan³ ${ }^{3}$ Mohammad Yasin ${ }^{4}$ \\ IAI Sunan Kalijogo Malang \\ ulum089@gmail.com 1, fitrotuljannah676@gmail.com ${ }^{2}$, denysetiawan3004@gmail.com 3, \\ mohammadyasin114@gmail.com 4
}

\begin{abstract}
Abstrak. Tujuan utama pelaksanaan pengabdian masyarakat ini adalah: 1) Memudahkan siswa dalam belajar membaca dan memahami Al-Qur'an guna hasil maksimal; 2) Meningkatkan minat dan kemampuan anak-anak dalam membaca Al-Quran; 3) Memberdayakan organisasi IPNU dan IPPNU untuk pengabdian masyarakat dan persiapan jangka panjang lembaga TPQ; 4) Membudayakan membaca Al-Qur'an sebagai wadah meminimalisir pengaruh buruk eraglobalisasi dan perkembangan IT yang sangat pesat, telah sepenuhnya terlaksana dengan baik. Pengabdian masyarakat ini dilakukan oleh mahasiswa KKN dan dosen DPL yang sudah memiliki basic pengajaran terkait program mengaji menggunakan metode iqro'. Pendampingan program mengaji menggunakan metode iqro' (tingkat dasar) pada anak-anak melalui pemberdayaan IPNU dan IPPNU di Desa Kenongo disambut baik dari berbagai kalangan baik dari pihak pengurus TPQ ataupun pihak IPNU dan IPPNU, dengan adanya kolaborasi antara lembaga pendidikan dan organisasi tersebut banyak memberikan dampak positif dan bisa meminimalisir permasalahan yang ada di lapangan khususnya terkait kekurangan pengajar.
\end{abstract}

Kata Kunci: Metode Iqro, Pengajar TPQ, Pemberdayaan IPNU dan IPPNU

Abstract. The main objectives of implementing this community service are: 1) Make it easier for students to learn to read and understand the Qur'an for maximum results; 2) Increase children's interest and ability in reading the Koran; 3) Empowering IPNU and IPPNU organizations for community service and long-term preparation of TPQ institutions; 4) Cultivating reading the Qur'an as a forum to minimize the negative effects of the era of globalization and the rapid development of IT, has been fully implemented well. This community service is carried out by KKN students and DPL lecturers who already have basic teaching related to the Koran program using the Iqro method. The mentoring of the Koran program using the iqro' method (basic level) for children through the empowerment of IPNU and IPPNU in Kenongo Village was welcomed by various groups, both from the TPQ management or IPNU and IPPNU parties, with collaboration between educational institutions and these organizations providing a lot of support. positive impact and can minimize problems in the field, especially related to the shortage of teachers.

Keywords: Iqro Method, TPQ Teachers, Empowerment of IPNU and IPPNU 


\section{PENDAHULAN}

Al-Qur'an adalah firman Allah yang telah diwahyukan kepada Rasulullah SAW melalui beberapa cara yang dikehendaki oleh Allah SWT yang memuat hukum-hukum Islam dan berisi tuntunan-tuntunan bagi umat manusia untuk mencapai kehidupan yang bahagia di dunia dan di akhirat, lahir maupun batin. Al-Qur'an merupakan sarana yang paling utama untuk bermunajat kepada Allah baik membaca, mempelajari, mengajarkan, serta mendengarkannya. Kesemuanya itu merupakan ibadah bagi setiap orang yang mengamalkannya. Mempelajari alQur'an adalah kewajiban, dengan demikian belajar membaca al-Qur'an adalah wajib bagi setiap orang Islam 1.

Allah SWT telah mengisyaratkan kepada seluruh umat manusia untuk banyak belajar berbagai hal untuk dapat membaca tanda-tanda kekuasaan Allah SWT yang ada dalam kehidupan, karena dengan membaca tentunya banyak menemukan hal-hal baru yang sangat bermanfaat sebagai bekal hidup di dunia dan di akhirat ${ }^{2}$. Islam dan pendidikan agama Islam merupakan bagian dari sistem pendidikan nasional di Indonesia dan selalu berjalan searah. Berbicara mengenai pendidikan, maka secara langsung maupun tidak langsung kita juga akan berbicara tentang pembelajaran banyak sekali hal yang harus diperhatikan guna mencapai hasil maksimal diantaranya adalah tempat, sarana prasarana, tenaga pengajar dan metode pembelajaran ${ }^{3}$.

Mengaji memiliki dasar makna membaca/mengikuti, bagi umat muslim aktivitas ini digunakan untuk mengkaji Al-Quran. Aktivitas ini dalam dalam agama islam ibadah merupakan satu- satunya petunjuk karena merupakan firman Allah sekaligus mendapat pahala. Belajar mengaji Al-Quran bagi keluarga muslim biasanya telah dimulai sejak usia kanak- kanak. Belajar dilakukan di masjid, surau atau mengundang guru mengaji kerumah, sehingga sejak menginjak usia baligh mereka telah lancer bahkan khatam ${ }^{4}$.

Berdasarkan penjelasan diatas dengan gemar mengaji sebuah program belajar dan membudayakan membaca Al-Quran dengan metode iqro'. Metode ini sudah diterapkan hampir

\footnotetext{
${ }^{1}$ Srijatun, “Implementasi Pembelajaran Baca Tulis Al- Qur ' an Dengan Metode Iqro Pada Anak Usia Dini Di RA Perwanida Slawi Kabupaten Tegal . Srijatun UIN Walisongo Semarang Pendahuluan Usia Dini Merupakan Periode Awal Yang Paling Penting Dan Mendasar Dalam Sepanjang" 11 (2017): 25-42.

2 Zulfitria and Zainal (Universitas Muhammadiyah Tangerang) Arif, "Penerapan Metode Iqro Sebagai Kemampuan Dasar Membaca Al-Qur'an Di TK Hiama Kids” (2017): 57-66.

${ }^{3}$ Yeni Rahmawati, "MEMBACA AL- QUR' AN DI TPQ AL HUSAINI REJASARI JURUSAN PENDIDIKAN AGAMA ISLAM FAKULTAS TARBIYAH DAN ILMU KEGURUAN INSTITUT AGAMA ISLAM NEGERI ( IAIN ) PURWOKERTO" (2017).

${ }^{4}$ Hendro Lisa et al., “PENDAMPINGAN PROGRAM MAGRIB MENGAJI PADA ANAK,” no. april 2020 (n.d.): 24-26.
} 
di seluruh wilayah Indonesia. Bahkan, sebagian Negara ASEAN juga menggunakan metode tersebut sebagai sarana dalam membaca Al-Qur'an. Hal tersebut membuktikan bahwa metode Iqro' sudah dipercaya oleh pihak dalam negeri maupun luar negeri yang berperan dalam proses pembelajaran membaca Al-Qur'an ${ }^{5}$.

Membaca Al- Quran sejak dulu telah menjadi budaya Indonesia dan merupakan hal baik yang harus dipertahankan di eraglobalisasi ini, oleh karena itu, pelaksanaan melakukan pendampingan agar program mengaji berjalan dan terlaksana secara berkesinambungan ${ }^{6}$. Adapun tujuan pendampingan “Mengaji Menggunakan Metode Iqro' (Tingkat Dasar) pada Anak-anak Melalui Pemberdayaan IPNU dan IPPNU di Desa Kenongo" adalah:

1. Memudahkan siswa dalam belajar membaca dan memahami Al-Qur'an guna hasil maksimal.

2. Meningkatkan minat dan kemampuan anak-anak dalam membaca Al-Quran.

3. Memberdayakan organisasi IPNU dan IPPNU untuk pengabdian masyarakat dan persiapan jangka panjang lembaga TPQ.

4. Membudayakan membaca Al-Qur'an sebagai wadah meminimalisir pengaruh buruk eraglobalisasi dan perkembangan IT yang sangat pesat.

\section{a. Analisis Situasi}

Desa Kenongo berada di dataran rendah dengan ketinggian tanah $450 \mathrm{M}$ dari permukaan air laut, merupakan bagian dari kecamatan Jabung Kabupaten Malang. Desa ini memiliki 2 dusun, yakni dusun Kenongo dan dusun Precet dimana setiap dusun terdiri dari 4 RW dan 29 RT, dengan jumlah penduduk 2744 Jiwa, yang terdiri 1394 Jiwa Laki-laki dan 1350 Jiwa petrempuan yang tergabung dalam 864 KK dengan mayoritas warga beragama Islam (Muslim). Banyak warga dari desa Kenongo yang masih berusia dini dan remaja yang sedang menempuh pendidikan baik formal maupun nonformal.

Desa Kenongo memiliki lembaga pendidikan nonformal, diantaranya yakni Taman Pendidikan Al-Qur'an. Terdapat 4 lembaga TPQ (Taman Pendidikan Al-Qur'an) yang sudah memiliki izin/legalitas dalam melaksanakan kegiatan, dimana 3 TPQ yang berada di dusun

\footnotetext{
5 Tsaqifa Taqiyya Ulfah, Muhammad Shaleh Assingkily, and Izzatin Kamala, “IMPLEMENTASI METODE IQRO' DALAM PEMBELAJARAN MEMBACA AL- QUR'AN" 2, no. 2 (2019): 59-69.

6 Lisa et al., "PENDAMPINGAN PROGRAM MAGRIB MENGAJI PADA ANAK"; Sri Maharani et al., "Pembelajaran Baca Tulis Al- Qur ' an Anak Usia Dini” 4 (2020): 1288-1298.
} 
Precet yakni TPQ Hidayatul Mubtadi'in, TPQ Al-Faqih, TPQ Roudlotul Ilmi dan 1 TPQ yang berada di dusun Kenongo yakni TPQ Nurul Jadid. Namun pada kenyataannya disetiap lembaga TPQ hanya terdapat 1 atau 2 pengajar saja, padahal untuk setiap TPQ setidahnya memilik siswa sebanyak 50-100 Siswa yang dapat kurang efektifnya pelaksanaan pembelajaran di TPQ.

\section{BAHAN DAN METODE}

Pengembangan lembaga adalah suatu usaha jangka panjang untuk memperbaiki proses-proses pemecahan masalah dan pembaharuan lembaga, terutama untuk keberlangsungan jangka panjang melalui pemberdayaan organisasi terkait yang efektif dan kolaboratif ${ }^{7}$. Program pengembangan TPQ di Desa Kenongo khususnya berkaitan dengan pengajar/guru diarahkan melalui pola pemberdayaan Organisasi IPNU (Ikatan Pelajar Nahdlotul Ulama') dan IPPNU (Ikatan Pelajar Putri Nahdlotul Ulama') karena khususnya daerah tersebut memiliki basis NU (Nahdlotul Ulama') yang sangat solid. Terdapat langkahlangkah pengembangan yang dapat dilakukan, diantaranya :

1. Melibatkan kawula muda IPNU dan IPPNU sebagai kolaborasi dalam pelaksanaan pembelajaran di TPQ untuk pemecahan masalah terkait kekurangan pengajar dan efektifitas hasil belajar.

2. Membudayakan pengabdian dan pengembangan lembaga TPQ jangka panjang melalui kolaborasi melalui pemberdaysaan orgnasisasi IPNU dan IPPNU.

3. Para pimpinan NU sebagai Organisasi besar dan Lembaga Pendidikan IAI Sunan Kalijogo sebagai institusi PTS yang satu lokasi diberi tugas khusus untuk terlibat langsung, perlu menginisiasi berbagai kegiatan pembelajaran di TPQ seperti KKN, KKP, PKL, PPL, pengabdian masyarakat dan matakuliah IAI SKJ melalui kerjasama dengan Lembaga TPQ untuk melakukan pemetaan dan advokasi persoalan di lapangan agar dapat mendorong terealisasinya program pengembangan berkelanjutan di lingkup TPQ.

\footnotetext{
7 Dedi Amrizal, "PENERAPAN METODE FAHIM QURAN ( TINGKAT DASAR ) PADA PENGAJIAN QU R' AN ANAK
} DAN REMAJA DI RANTING MUHAMMADIYAH MENUJU PEMBERDAYAAN CABANG DAN" 2, no. 1 (2018). 
Lokasi tempat diadakannya pengabdian kepada masyarakat ini adalah lokasi yang jamak dimiliki oleh TPQ dimana kebanyakan pelaksanaan dilaksanakan di Masjid. Salah satu cirinya adalah kurangnya perhatian masyarakat terhadap aktivitas keagamaan membuat organisasi kurang ikut andil didalam pelaksanaan pelayanan masyarakat. Keberadaan mesjid yang menjadi sentral aktivitas keagamaan dan pemberdayaan organisasi IPNU dan IPPNU menjadi solusi alternatif bagi kurangnya tenaga pengajar di TPQ. Kegiatan pelatihan dan pembinaan kepada remaja dan pemuda IPNU dan IPPNU ini adalah upaya serius kita untuk keberlangsungan TPQ jangka panjang dan hasil belajar yang lebih baik kedepannya.

Program ini menjadikan mesjid ataupun TPQ sebagai sentral kegiatan pembinaan dan pemberdayaan anggota dan perekrutan anggota muda yang ada ditengah tengah masyarakat khususnya NU. Kekurangan tenaga pengajar dan penggerak untuk mengajar dan membina para remaja di TPQ desa Kenongo, diharapkan terjawab dengan pelaksanaan kegiatan Pengabdian kepada Masyarakat ini.

Pelaksanaan program pengabdian masyarakat ini dilakukan oleh mahasiswa KKN dan dosen DPL yang sudah memiliki basic pengajaran terkait program mengaji menggunakan metode iqro'. Hampir keseluruhan mahasiswa KKN merupakan bagian dari masyarakat Kec. Jabung dan juga merupakan bagian dari Pondok Sunan Kalijogo Malang, lokasi TPQ dan pemberdayaan IPNU dan IPPNU guna pengajaran di TPQ dapat dilakukan berkesinambungan perbaikan lembaga TPQ jangka panjang.

Pelaksanaan Program Mengaji Menggunakan Metode Iqro'

Iqro terdiri dari 6 jilid, pembelajaran melalui sistematika mulai iqro' jilid 1 hingga jilid 6 memberi kemudahan siswa secara perlahan belajar al-Qur'an. Sehingga dipandang tepat setiap tingkatan yang dilalui anak semakin memotivasi mereka dalam belajar al-Qur'an ${ }^{8}$. Pembelajaran Al-Qur'an metode Iqro' memiliki kelebihan antara lain: 1) Metode Iqro' sudah diterapkan di seluruh penjuru Indonesia dan sebagian Negara ASEAN seperti Malaysia dan Thailand; 2) Buku penunjang (buku Iqro') mudah didapatkan dimana saja dan harganya sangat terjangkau; 3) Menggunakan sistem CBSA (Cara Belajar Siswa Aktif); 4) Metode Iqro' fleksibel dalam peningkatan jilid. Jika santri sudah mengeluarkan kemampuan dengan maksimal namun belum dapat membaca huruf hijaiyah tertentu misal santri selalu terbalik dalam mengucapkan

\footnotetext{
${ }^{8}$ Ulfah, Assingkily, and Kamala, “IMPLEMENTASI METODE IQRO' DALAM PEMBELAJARAN MEMBACA ALQUR'AN."
} 


\section{Khidinatuna \\ Jurnal Penelitian dan Pengabdian Hepada Masuarahat \\ Institut Agama Islam Sunan Kalijogo Malang \\ P-ISSN: 2721-9607/ E-ISSN: 2721-947X \\ Volume 2 Nomor 2 Desember2021}

huruf ba dan na. Namun ketika santri dimohon untuk membaca huruf yang lain ternyata bisa, maka santri dapat dinaikkan ke tingkat jilid selanjutnya; 5) Dalam waktu 6-8 bulan santri TKATPA dapat khatam Iqro' dan melanjutkan ke tingkat Al-Qur'an walau membacanya masih pelan; 6) Praktis, karena ustadz/ah langsung dapat memahami kemampuan santri; 7) Metode Iqro' bersifat sistematis, disusun berdasarkan kemampuan yang berbeda. Metode Iqro' disusun dari yang konkret menuju abstrak, diawali dari yang mudah menuju sulit, dan dimulai dari yang sederhana menjadi kompleks.

Mahasiswa KKN secara terjadwal membantu mengajar TPQ di Desa Kenongo dengan metode iqro'. Tahan awal program ini dilaksanakan agar mempermudah dan meningkatkan pemahaman terkait baca Al-Qur'an serta dapat mengatasi kurangnya tenaga pengajar di TPQ, sembari melakukan kaderisasi dan pemberdayaan IPNU dan IPPNU, karena memang tidak sedikit mahasiswa yang juga tergabung dalam organisasi tersebut. Secara tidak langsung pemberdayaan dan pengkaderan dalam mengatasi kuranynya tenaga di TPQ bisa diatasi secara pelan-pelan. Selain itu mahasiswa juga memberikan materi tambahan serta meningkatkan motivasi murid-murid TPQ untuk terus belajar Al-Qur'an.
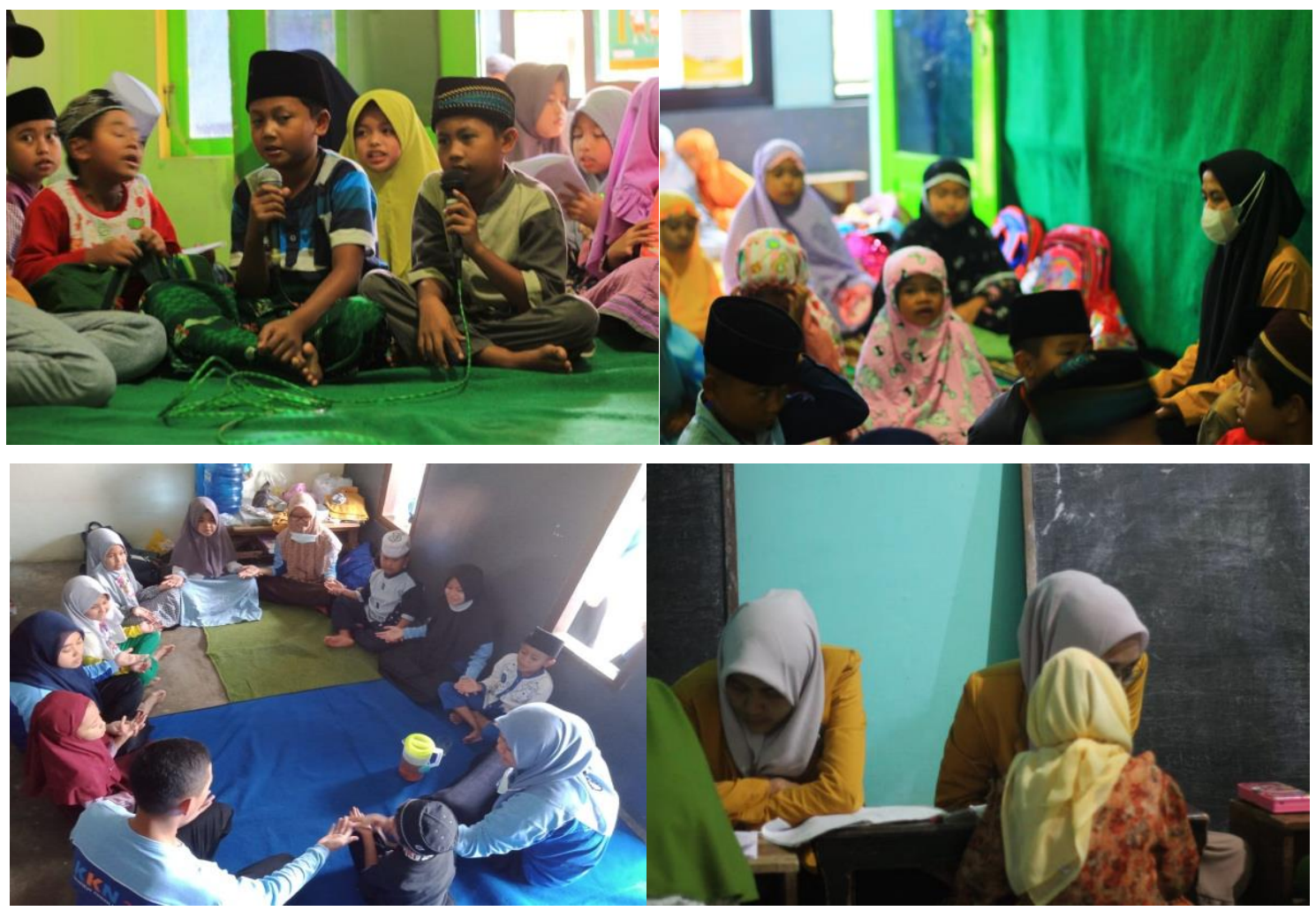

Gambar 1. Pelaksanaan program mengaji dengan metode iqro' oleh mahasiswa KKN 


\section{Khidmatuina \\ Jurnal Penelitian dan Pengabdian Hepada Masuarahat \\ Institut Agama Islam Sunan Kalijogo Malang \\ P-ISSN: 2721-9607/ E-ISSN: 2721-947X \\ Volume 2 Nomor 2 Desember2021}

\section{a. Kelengkapan Sarana-prasarana TPQ}

Selain memperhatikan kebutuhan tenaga pengajar pada TPQ, mahasiswa KKN juga melakukan program terkait kelengkapan sarana dan prasarana di TPQ guna perbaikan kelembagaan. Program ini dilaksankan mahasiswa KKN dengan tujuan untuk melengkapi sarana dan prasarana antara lain: 1) Pembuatan rak sandal; 2) pembuatan plang arah menuju TPQ; 3) Pembuatan plakat nama TPQ beserta nomor registrasinya.

Program ini di laksanakan mahasiswa KKN dengan harapan untuk memberi motivasi kepada anak - anak TPQ untuk lebih tertib lagi dalam menata sandal/ sepatunya senidiri - sendiri. Mempermudah masyarakat dalam menuju lembaga pendidikan TPQ terdekat dan sebagai penunjuk bahwasanya terdapat sebuah lembaga TPQ/promosi, dan menunjukkan bahwasanya TPQ yang berdiri merupakan lembaga legal yang memiliki nomor registrasi dari KEMENAG (Kementerian Agama) agar masyarakat lebih yakin dan percaya.
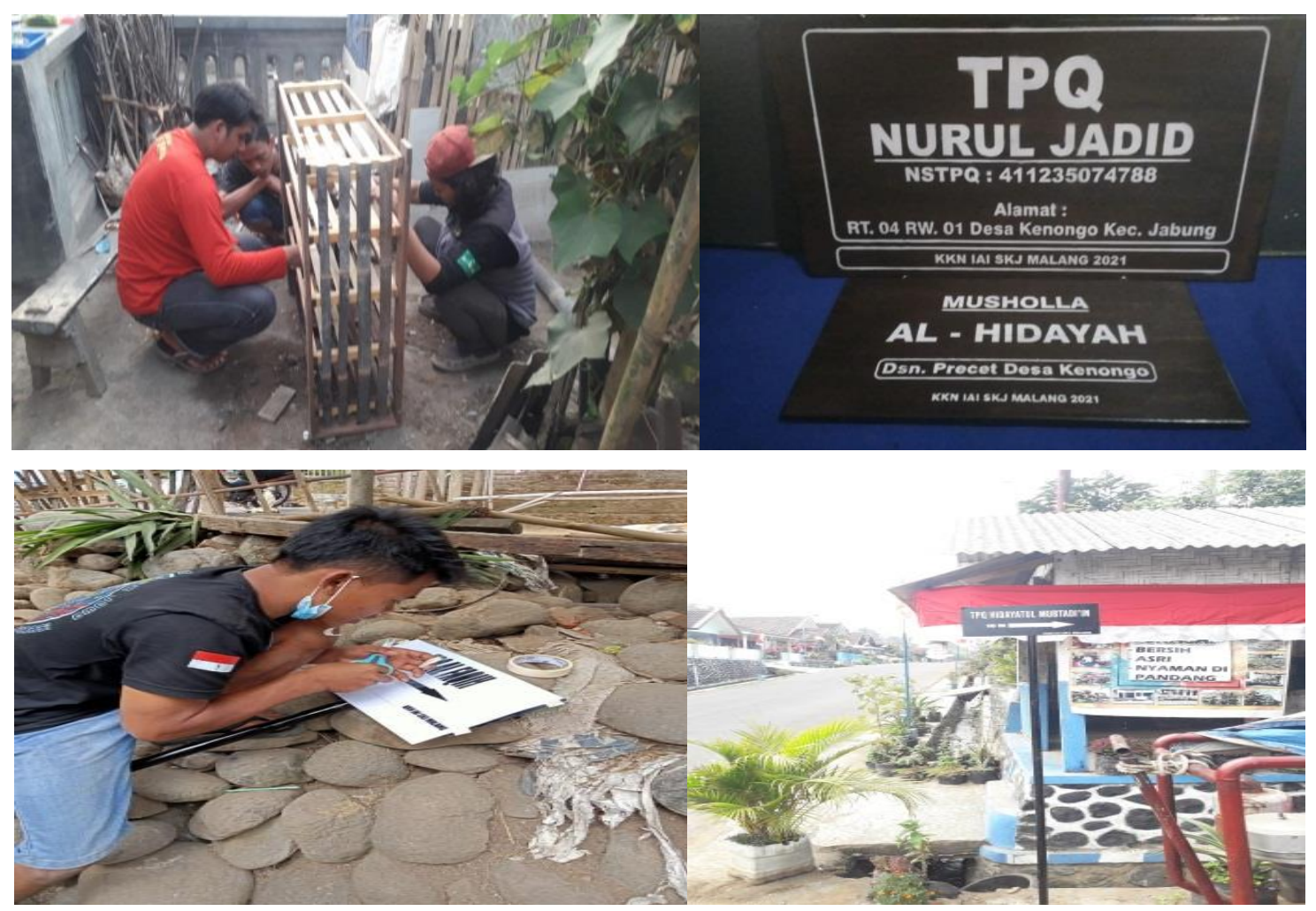

Gambar 2. Persiapan dan Pelaksanaan Sarpras TPQ 


\section{Khidinatuna \\ Jurnal Penelitian dan Pengabdian Hepada Masuarahat \\ Institut Agama Islam Sunan Kalijogo Malang \\ P-ISSN: 2721-9607/ E-ISSN: 2721-947X \\ Volume 2 Nomor 2 Desember2021}

\section{b. Pengkaderan Pengajar Melalui Pemberdayaan IPNU dan IPPNU}

Pengkaderan ini dimulai dari pelaksanaan pemetaan potensi sumber daya manusia yang akan diberdayakan dalam pengajaran membaca Al-Qur'an di TPQ untuk menerapkan metode iqro' di desa Kenongo yang menjadi lokasi pengabdian kepada masyarakat ini. Selanjutnya dilakukan pengkaderan dengan tiga aktivitas sebagai berikut: 1) Silaturahmi dengan organisasi IPNU dan IPPNU yang ada di desa Kenongo, serta menyampaikan permasalahan yang ada di lapangan; 2) Penyamaan persepsi program bersamaan dengan pelaksanaan mengajar tingkat dasar menyangkut kemampuan membaca, menghafal, mengartikan, dan memahami Al-Qur'an dengan baik; 3) Penerapan metode iqro dalam pengajaran di TPQ yang membutuhkan pengajar. Hal ini juga dilaksanakan bersama dengan pengurus TPQ sehingga kolaborasi bisa berjalan maksimal dan berkesinambungan untuk mengatasi kekurangan pengajar di TPQ.

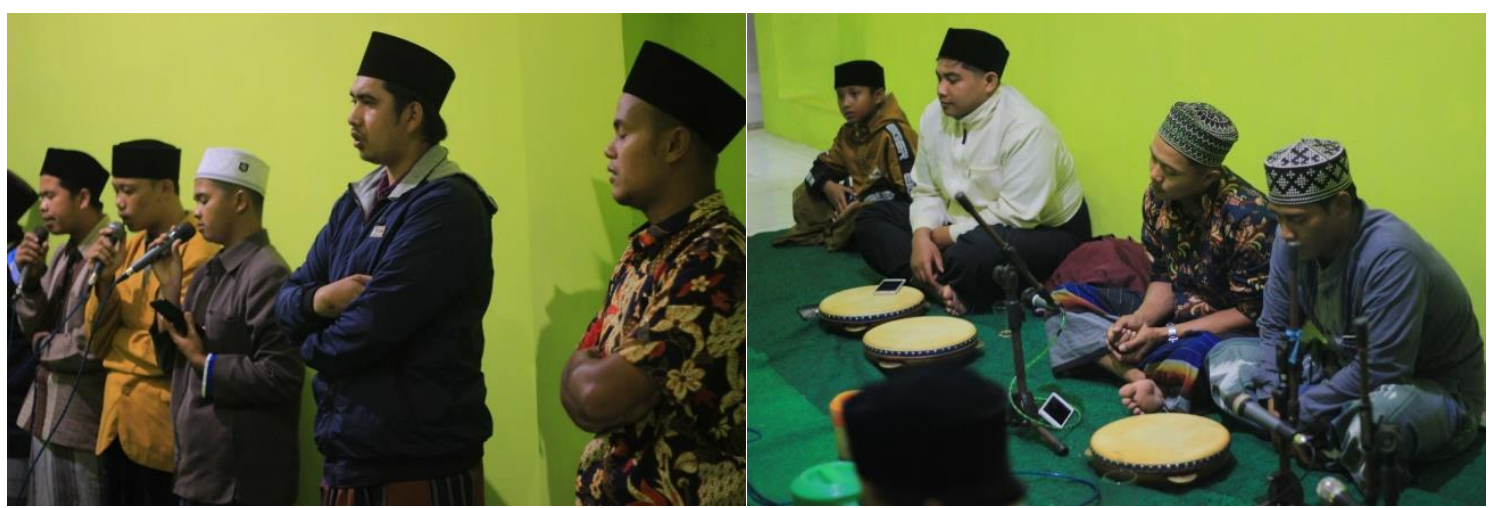

Gambar 3. Silaturahmi dengan IPNU dan koordinasi tahap Awal

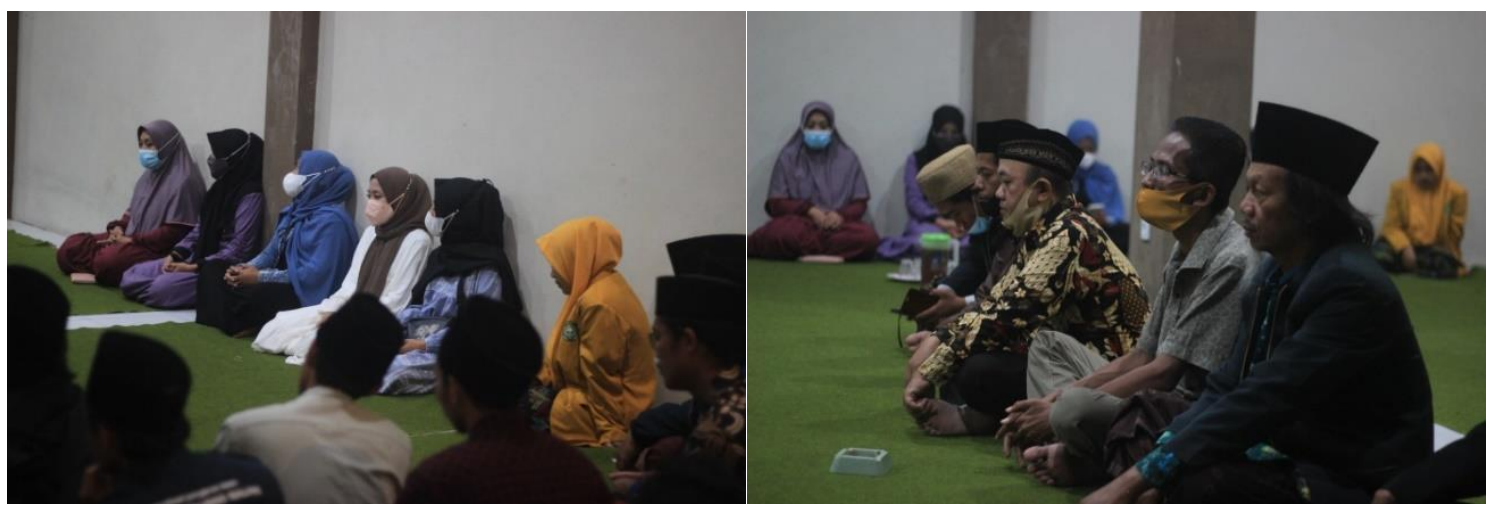

Gambar 4. Koordinasi Bersama IPNU, IPPNU dan pengurus TPQ dan dihadiri perangkat desa Kenongo 


\section{HASIL DAN PEMBAHASAN}

Kuliah Kerja Nyata (KKN) merupakan bentuk pengabdian yang bersifat nyata yang dilakukan oleh mahasiswa kepada masyarakat yang sebenarnya, setelah mahasiswa mendapatkan pengetahuan, keterampilan, dalan lainnya yang diharapkan bermanfaat bagi masyarakat. Berdasarkan tema KKN "Bersama Masyarakat Memberi Manfaat", diharapkan dalam setiap kegiatan pengabdiannya pada masyarakat di desa Kenongo dapat memberikan manfaat yang bisa dirasakan untuk seluruh lapisan masyarakat dengan jangka panjang. Pengabdian yang dilakukan ditekankan kepada pendidikan, khususnya pendidikan nonformal pada Taman Baca Al-Qur'an (TPQ) guna meningkatkan keilmuan masyarakat dan anak-anak muda serta remaja. Selain karena pentingnya belajar agaman, hal ini juga didasarkan kepada keinginan Kampus IAI SKJ yang terfokus sebagai pusat kajian ilmu pengetahuan serta berwawasan Islam moderat untuk membentuk generasi cerdas, Indonesia emas.

Pendampingan program mengaji menggunakan metode iqro' (tingkat dasar) pada anak-anak melalui pemberdayaan IPNU dan IPPNU di Desa Kenongo disambut baik dari berbagai kalangan baik dari pihak pengurus TPQ ataupun pihak IPNU dan IPPNU, dengan adanya kolaborasi antara lembaga pendidikan dan organisasi tersebut banyak memberikan dampak positif dan bisa meminimalisir permasalahan yang ada di lapangan khususnya terkait kekurangan pengajar. Setelah dilakukan evaluasi harian, pekanan dan sekarang bulanan oleh mahasiswa KKN melalui absen dan foto, terlihat bahwa kegiatan belajar di TPQ berjalan baik dan lancar serta kekurangan guru sudah terselesaikan.

\section{KESIMPULAN}

Pelaksanaan pengabdian masyarakat ini telah menyelesaikan seluruh tahapan yang direncanakan. Tujuan utama pelaksanaan pengabdian masyarakat ini adalah: 1) Memudahkan siswa dalam belajar membaca dan memahami Al-Qur'an guna hasil maksimal; 2) Meningkatkan minat dan kemampuan anak-anak dalam membaca Al-Quran; 3) Memberdayakan organisasi IPNU dan IPPNU untuk pengabdian masyarakat dan persiapan jangka panjang lembaga TPQ; 4) Membudayakan membaca Al-Qur'an sebagai wadah meminimalisir pengaruh buruk eraglobalisasi dan perkembangan IT yang sangat pesat, telah sepenuhnya terlaksana dengan baik. 
Tahapan kerja pengabdian masyarakat ini di mulai dari pembentukan tim mahasiswa KKN, dilanjutkan dengan identifikasi kebutuhan lapangan dan permasalahan lapangan terkait TPQ di desa Kenongo, dilakukan pengkaderan dengan tiga aktivitas sebagai berikut: 1) Silaturahmi dengan organisasi IPNU dan IPPNU yang ada di desa Kenongo, serta menyampaikan permasalahan yang ada di lapangan; 2) Penyamaan persepsi program bersamaan dengan pelaksanaan mengajar tingkat dasar menyangkut kemampuan membaca, menghafal, mengartikan, dan memahami Al-Qur'an dengan baik; 3) Penerapan metode iqro dalam pengajaran di TPQ yang membutuhkan pengajar, sehingga kolaborasi bisa berjalan maksimal dan berkesinambungan untuk mengatasi kekurangan pengajar di TPQ serta dilakukan evaluasi (harian, pekanan dan bulanan) guna perbaikan program jika terdapat kendala. 


\section{DAFTAR PUSTAKA}

Amrizal, Dedi. "PENERAPAN METODE FAHIM QURAN ( TINGKAT DASAR ) PADA PENGAJIAN QU R' AN ANAK DAN REMAJA DI RANTING MUHAMMADIYAH MENUJU PEMBERDAYAAN CABANG DAN" 2, no. 1 (2018).

Lisa, Hendro, Pendidikan Guru, Madrasah Ibtidaiyah, and Ekonomi Syariah. "PENDAMPINGAN PROGRAM MAGRIB MENGAJI PADA ANAK," no. april 2020 (n.d.): 2426.

Maharani, Sri, Pendidikan Guru, Pendidikan Anak, Usia Dini, and Universitas Negeri Padang. “Pembelajaran Baca Tulis Al- Qur' an Anak Usia Dini” 4 (2020): 1288-1298.

Rahmawati, Yeni. “MEMBACA AL- QUR' AN DI TPQ AL HUSAINI REJASARI JURUSAN PENDIDIKAN AGAMA ISLAM FAKULTAS TARBIYAH DAN ILMU KEGURUAN INSTITUT AGAMA ISLAM NEGERI ( IAIN ) PURWOKERTO" (2017).

Srijatun. "Implementasi Pembelajaran Baca Tulis Al- Qur' an Dengan Metode Iqro Pada Anak Usia Dini Di RA Perwanida Slawi Kabupaten Tegal . Srijatun UIN Walisongo Semarang Pendahuluan Usia Dini Merupakan Periode Awal Yang Paling Penting Dan Mendasar Dalam Sepanjang" 11 (2017): 25-42.

Ulfah, Tsaqifa Taqiyya, Muhammad Shaleh Assingkily, and Izzatin Kamala. "IMPLEMENTASI METODE IQRO' DALAM PEMBELAJARAN MEMBACA AL- QUR'AN" 2, no. 2 (2019): 5969.

Zulfitria, and Zainal (Universitas Muhammadiyah Tangerang) Arif. "Penerapan Metode Iqro Sebagai Kemampuan Dasar Membaca Al-Qur'an Di TK Hiama Kids” (2017): 57-66. 